\title{
Ovarian and feto-placental factors and the regulation of prolactin release during pregnancy in the rat
}

\author{
G. A. Jahn, N. Alonso and R. P. Deis \\ Laboratorio de Reproduccion y Lactancia, CRIC YT-CONICET, Casilla de Correo 855, Mendoza, \\ Argentina
}

\begin{abstract}
Summary. Administration of progesterone $(5$ or $10 \mathrm{mg}$ ) to pregnant rats increased serum prolactin significantly on the afternoon of Days $4,6,7$ and 8 of pregnancy, but had no effect on later days. On Day 10 progesterone administration increased serum prolactin only in rats treated with oestrogen the day before. A similar treatment with oestrogen and progesterone was unable to stimulate secretion on the afternoon of Day 13 of pregnancy. In rats from which the corpora lutea had been unilaterally removed and hence endogenous progesterone levels were $50 \%$ of the normal values, or in those that carried 4 conceptuses, progesterone treatment after oestradiol priming was partly effective in inducing prolactin release on Day 13. However, in rats ovariectomized, with bilateral excision of the corpora lutea, or with 2 conceptuses left, treatment with ovarian steroids markedly increased serum prolactin values. By Day 13 all the rats from the ovariectomized group or with bilateral excision of the corpora lutea had aborted. On Day 13, therefore, the high serum concentrations of feto-placental factors and of progesterone are responsible for the blockade of the spontaneous and ovarian steroidinduced prolactin release. On the other hand, on Day 16 of pregnancy the decrease of circulating progesterone by excision of the corpora lutea or by ovariectomy followed by oestradiol treatment significantly increased serum prolactin on Day 17. Removal of all the conceptuses did not modify the effects of these treatments.

The present results demonstrate different roles of progesterone upon the control of prolactin secretion. After a stimulatory action during the first days of pregnancy, there is a change to an inhibitory control at the end of pregnancy. At mid-pregnancy the association of maximal circulating concentrations of fetal-placental factors and progesterone prevents the spontaneous and ovarian steroid-induced release of prolactin.
\end{abstract}

\section{Introduction}

Fertile mating in the rat induces two daily surges of prolactin, one at the end of the light period (diurnal) and the other at the end of the dark period (nocturnal), which are last seen on Days 9 (diurnal) and 10 (nocturnal) of pregnancy (Smith \& Neill, 1976). On Day 9 placental lactogen is already detectable in the serum and peaks on Day 12 (Kelly, Shiu, Robertson \& Friesen, 1975; Robertson \& Friesen, 1981; Tonkowicz \& Voogt, 1983). This factor is generally held to be responsible for the disappearance of both prolactin surges (Yogev \& Terkel, 1978; 1980; Voogt, Robertson \& Friesen, 1982; Tonkowicz \& Voogt, 1983; 1984; Tonkowicz, Robertson \& Voogt, 1983).

The surges of prolactin induced by mating (pregnancy or pseudopregnancy) are also dependent upon certain levels of oestrogen and progesterone (Alonso, 1974; de Greef \& Zeilmaker, 1978; Freeman \& Sterman, 1978; Murakami, Takahashi \& Suzuki, 1979; Gorospe \& Freeman, 1981, 
1982; Deis \& Alonso, 1985). The interaction of these factors has been well established in the regulation of the nocturnal surge (Voogt, 1980), while the diurnal surge has been less studied, and its regulation seems to be different from that of the nocturnal surge, at least in pseudopregnant rats (Gorospe \& Freeman, 1981; 1982; Deis \& Alonso, 1985).

Progesterone is an important factor for the maintenance and enhancement of prolactin surges during pregnancy and pseudopregnancy (de Greef \& Zeilmaker, 1978; Murakami et al., 1979; Deis \& Alonso, 1985). However, chronically elevated progesterone concentrations inhibit prolactin release and oestrogen action during late pregnancy (Vermouth \& Deis, 1972; 1974; Bussmann \& Deis, 1979). After an initial stimulatory effect progesterone blocks subsequent spontaneous, oestrogen- or oestrogen plus progesterone-induced prolactin release in ovariectomized or prooestrous rats (Alonso, 1974; Caligaris, Astrada \& Taleisnik, 1974).

The aim of the present study was to determine the role of progesterone and fetoplacental factors on the regulation of prolactin release during early and midpregnancy in the rat.

\section{Materials and Methods}

Virgin female rats bred in our laboratory (originally Wistar strain) weighing $180-220 \mathrm{~g}$ at the onset were used in all the experiments. They were kept in a light (06:00-20:00 h lights on) and temperature $\left(22-24^{\circ} \mathrm{C}\right)$ controlled room and fed standard rat chow (Purina) and water ad libitum.

Vaginal smears were taken daily and rats were made pregnant by caging individually with fertile males on the night of pro-oestrus, and the presence of spermatozoa was checked in the vaginal smear the following morning. This day was counted as Day 1 of pregnancy.

Surgical procedures. All surgical procedures were performed under ether anaesthesia between 10:00 and 11:00 h on Day 11 or at 09:00 h on Day 16 of pregnancy. Ovariectomy was performed through two dorso-lateral incisions. For excision of corpora lutea the ovarian bursae were opened and the corpora lutea were removed by miniature forceps with the aid of magnifying lenses. Ablation of different numbers of feto-placental units was performed through a midline abdominal incision; the uterus was exposed and the fetuses and placentae were removed through small slits made in the antimesometrial side of the uterus. Sham operations were performed in a similar manner without removing the ovaries or the corpora lutea, and by cutting the uterus between the implantation sites. At autopsy the ovaries and uteri were inspected to ascertain the presence of any remaining ovarian tissue and corpora lutea, and for fetal viability and growth.

Blood samples were obtained by cardiac puncture of the conscious animals or by decapitation. The blood was allowed to clot at room temperature and serum was separated and stored frozen $\left(-30^{\circ} \mathrm{C}\right)$ until assayed for prolactin and progesterone.

Drugs. Oestradiol benzoate (1 or $2 \mu \mathrm{g} / \mathrm{rat}$ : Schering, Argentina) and progesterone (5 or $10 \mathrm{mg} /$ rat: Roussel-UCLAF, France) were given s.c. in $0.2 \mathrm{ml}$ of purified sunflower seed oil at the times indicated in the text.

Hormone assay. Prolactin was measured by radioimmunoassay, using the materials kindly provided by NIADDK. Prolactin was radioiodinated by the chloramine $\mathrm{T}$ method. Results are expressed in terms of the rat prolactin standard preparation RP-1. Serum progesterone was measured using a radioimmunoassay developed in our laboratory (Bussmann \& Deis, 1979) with an antiserum raised against progesterone-11-BSA conjugate in rabbits. The sensitivities of the assays are $3 \mathrm{ng}$ prolactin $/ \mathrm{ml}$ and $<0.5 \mathrm{ng}$ progesterone $/ \mathrm{ml}$. The inter- and intra-assay coefficients of variation for both hormones were $<10 \%$. Prolactin does not cross-react with placental lactogen (Robertson \& Friesen, 1981).

Statistical analysis. This was performed using one- or two-way analysis of variance followed by a $t$ test to check the significance of the differences between means (Snedecor \& Cochran, 1967). 


\section{Results}

Steroids and serum prolactin concentrations on different days of pregnancy

Serum prolactin concentrations measured at 18:00 h on Days $4,6,7$ and 8 of pregnancy were significantly higher when compared to values obtained at 17:00 h. On Days 10,13,15, 18 and 21, circulating prolactin was very low and the values were similar at 17:00 and 18:00 h (Fig. 1).

The administration of progesterone $(10 \mathrm{mg})$ at $13: 00 \mathrm{~h}$ on Days $4,6,7$ or 8 of pregnancy induced a significant increase in serum prolactin concentration at $17: 00 \mathrm{~h}$, and at 18:00 h only on Days 4 and 6. After Day 10 of pregnancy, no stimulatory effect of progesterone on circulating prolactin was obtained (Fig. 1).

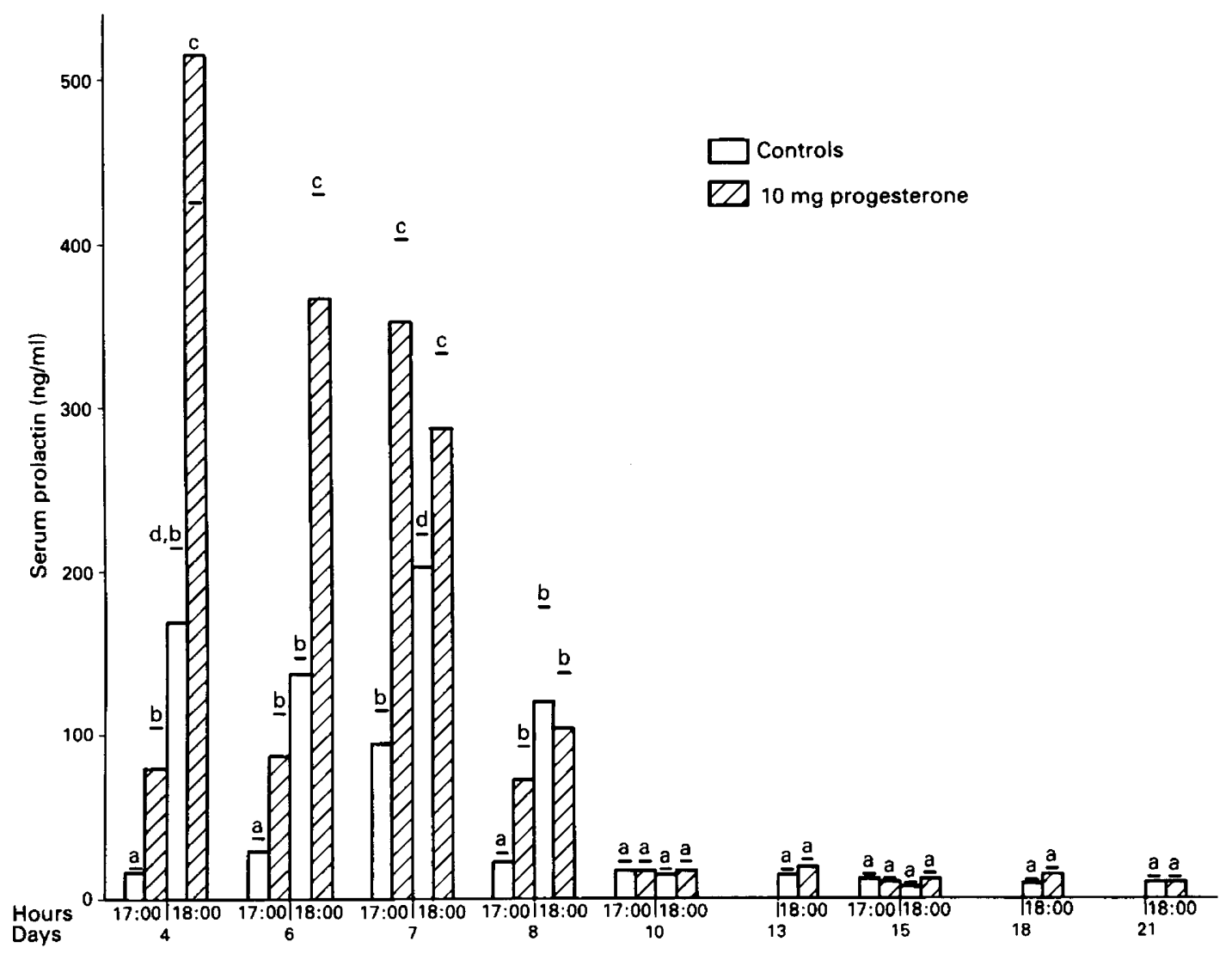

Fig. 1. Effect of progesterone $(10 \mathrm{mg})$ given at $13: 00 \mathrm{~h}$ on serum prolactin concentration measured at 17:00 and 18:00 h on different days of pregnancy. Values are mean \pm s.e.m. of groups of 6-10 animals; values with different letters are significantly different, $P<0.05$.

Some groups of rats were treated with $5 \mathrm{mg}$ progesterone and the stimulatory effect of the steroid on serum prolactin levels was not different from that obtained with a dose of $10 \mathrm{mg}$ (Day $6,17: 00 \mathrm{~h}, 114 \pm 35 \mathrm{ng} / \mathrm{ml}(\mathrm{N}=4) ;$ Day $7,17: 00 \mathrm{~h}, 165 \pm 5 \mathrm{ng} / \mathrm{ml}(\mathrm{N}=4) ;$ Day 8, 17:00 h, $157 \pm 34 \mathrm{ng} / \mathrm{ml}(\mathrm{N}=8))$. In subsequent experiments, therefore, the progesterone dose used was $5 \mathrm{mg} / \mathrm{rat}$.

Administration of oestradiol benzoate alone $(2 \mu \mathrm{g} / \mathrm{rat})$ at 17:00 $\mathrm{h}$ on Day 9 , did not affect the 
serum prolactin concentration measured at $18: 00 \mathrm{~h}$ on Day 10. Progesterone, injected on Day 10 to oestrogen-primed pregnant rats, induced a significant increase in serum prolactin concentration only when injected at 13:00 h (Fig. 2). On Day 13, when serum progesterone values were more than double those of Day 10, none of the above indicated treatments (oestrogen at 17:00 h on Day 12, progesterone at 10:00 or 13:00 h on Day 13) was able to increase serum prolactin at 18:00 h (Fig. 3).

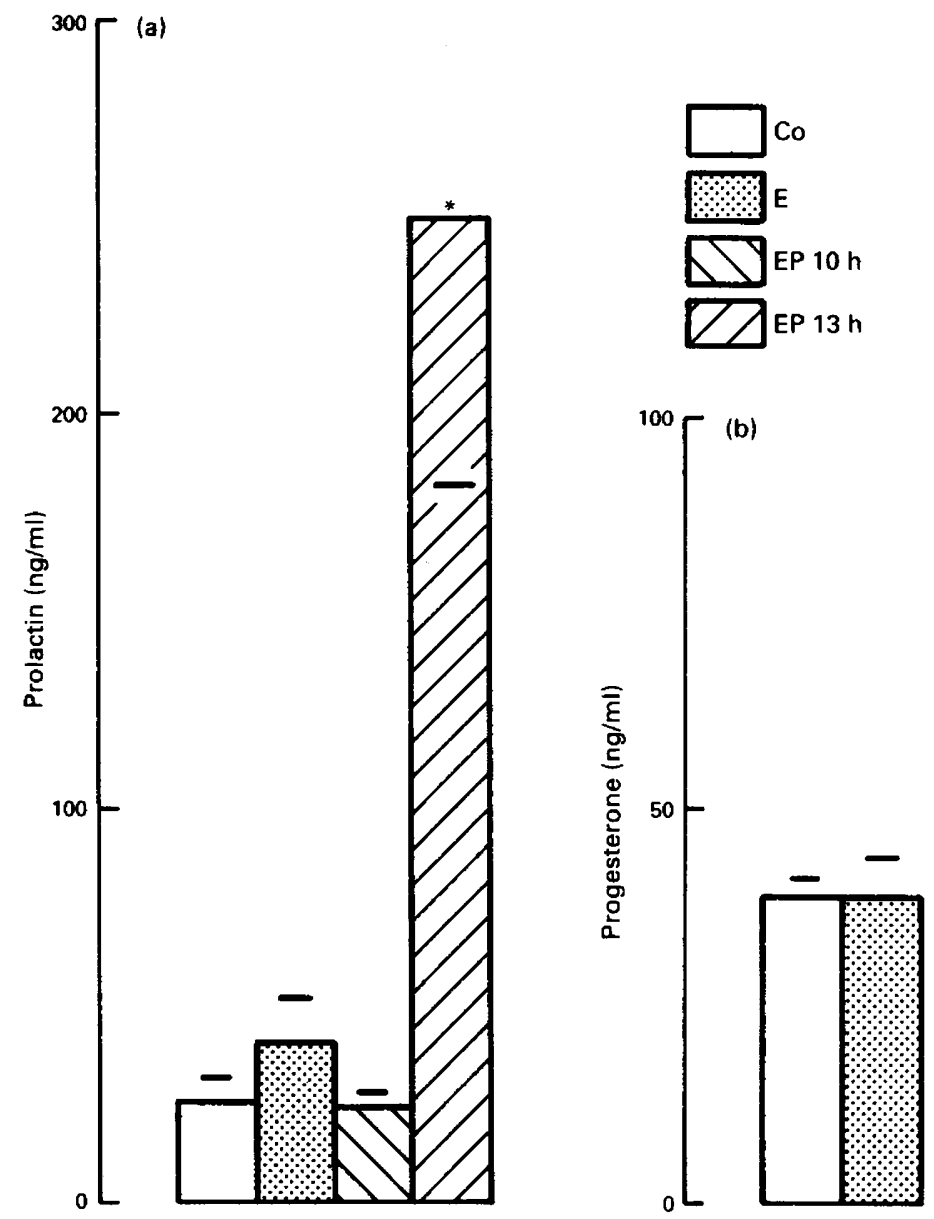

Fig. 2. Serum prolactin (a) and progesterone (b) concentrations in rats at 18:00 h on Day 10 of pregnancy after treatments with oestradiol $(2 \mu \mathrm{g}$, s.c. at 17:00 h on Day 9) and progesterone $(5 \mathrm{mg}$, s.c. at 10:00 or 13:00 h on Day 10). Values are mean \pm s.e.m. of groups of 7-8 animals. ${ }^{*} P<0.01$ as compared with controls and others.

\section{Steroids and prolactin concentrations after ovariectomy or excision of corpora lutea}

To ascertain whether the high values of serum progesterone seen on Days 13-15 of pregnancy have a role in the inhibition of prolactin release, the corpora lutea were excised unilaterally from pregnant rats on Day 11 to obtain a partial decrease of circulating progesterone concentration. Serum prolactin and progesterone concentration were measured at 18:00 h on Days 13, 14 and 15 (Table 1). Serum progesterone values fell in the experimental rats to values similar to those observed on Day 10 of pregnancy (see Fig. 2) but serum prolactin concentration did not change significantly. 

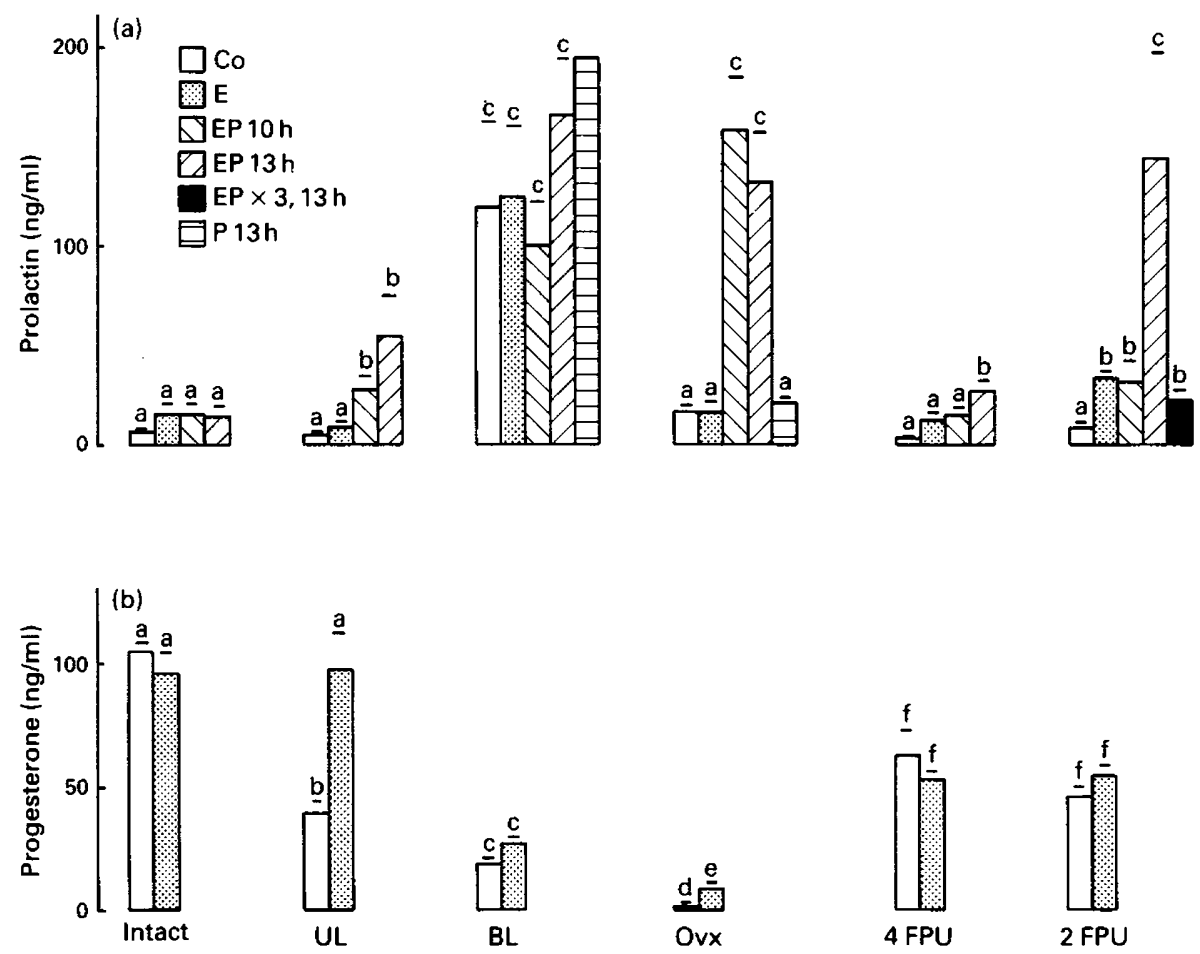

Fig. 3. Effect of different surgical procedures on the morning of Day 11 and treatments with oestradiol and progesterone on serum prolactin (a) and progesterone (b) concentrations at 18:00 h on Day 13 of pregnancy. E: $2 \mu$ g oestradiol, s.c. at 17:00 h on Day 12; P: 5 mg progesterone, s.c. at 10:00 or 13:00 h on Day 13; EP: $2 \mu \mathrm{g}$ oestradiol, s.c. at 17:00 h on Day 12 and progesterone, $5 \mathrm{mg}$, s.c. at 10:00 or 13:00 h on Day 13; EP $\times$ 3: progesterone, $5 \mathrm{mg}$, s.c. daily at $13: 00 \mathrm{~h}$ on Days 11,12 and 13 and oestradiol $2 \mu \mathrm{g}$, s.c. at 17:00 h on Day 12. Intact: sham-operated controls; UL: unilateral excision of corpora lutea; BL: bilateral excision of corpora lutea; Ovx: ovariectomy; 4 FPU: 4 remaining conceptuses; 2 FPU: 2 remaining conceptuses. Values are mean \pm s.e.m. for $6-10$ animals; values with different letters are significantly different, $P<0.05$.

Table 1. Effect of unilateral excision of $\mathrm{CL}$ on serum prolactin and progesterone concentrations at 18:00 h on Days 13, 14 and 15 of pregnancy in rats

\begin{tabular}{|c|c|c|c|c|c|c|}
\hline & \multicolumn{3}{|c|}{ Serum prolactin $(\mathrm{ng} / \mathrm{ml})$} & \multicolumn{3}{|c|}{ Serum progesterone $(\mathrm{ng} / \mathrm{ml})$} \\
\hline & Day 13 & Day 14 & Day 15 & Day 13 & Day 14 & Day 15 \\
\hline Intact & $6 \cdot 7 \pm 0 \cdot 3(8)$ & $7 \cdot 0 \pm 0 \cdot 3(6)$ & $5 \cdot 6 \pm 0 \cdot 4(6)$ & $104 \pm 10(8)$ & $90 \pm 7(6)$ & $73 \pm 7(6)$ \\
\hline CL removal & $8 \cdot 1 \pm 0 \cdot 3(6)$ & $9.0 \pm 0.9(6)$ & $5.6 \pm 0.5(6)$ & $44 \pm 5(6)^{*}$ & $36 \pm 1(6)^{*}$ & $50 \pm 8(6)^{* *}$ \\
\hline
\end{tabular}

Values are mean \pm s.e.m. for the no. of animals in parentheses.

${ }^{*} P<0.01,{ }^{* *} P<0.05$ compared with the intact group on the same day. 
When experimental rats (unilateral excision of corpora lutea) were treated with oestradiol $(2 \mu \mathrm{g}$ given at 17:00 h on Day 12) and progesterone (given at 10:00 or 13:00 h on Day 13) serum prolactin concentrations were significantly higher at $18: 00 \mathrm{~h}$ on Day 13. Oestrogen $(2 \mu \mathrm{g})$ treatment alone did not modify serum prolactin values but serum progesterone increased to concentrations similar to those in intact rats.

Bilateral excision of corpora lutea on Day 11 induced partial resorption of the conceptuses and vaginal bleeding $24 \mathrm{~h}$ later. The uteri were filled with blood and showed ballooning. Serum progesterone values were below $20 \mathrm{ng} / \mathrm{ml}$. Serum prolactin values were increased in this group and the treatments with ovarian steroids did not modify them further (Fig. 3).

Rats ovariectomized on Day 11 also showed resorption of the conceptuses $24 \mathrm{~h}$ after surgery, but the uteri were less filled with blood, there was no ballooning and serum progesterone values were below $5 \mathrm{ng} / \mathrm{ml}$. Serum prolactin concentrations at 18:00 h on Day 13 in this group were not different from those of intact rats and treatments with oestradiol or progesterone alone had no effect. Treatment with oestradiol plus progesterone (given at 10:00 or 13:00 h on Day 13) led to significantly higher serum prolactin concentrations with values similar to those of rats from which the corpora lutea had been bilaterally removed (see Fig. 3 for details of treatments).
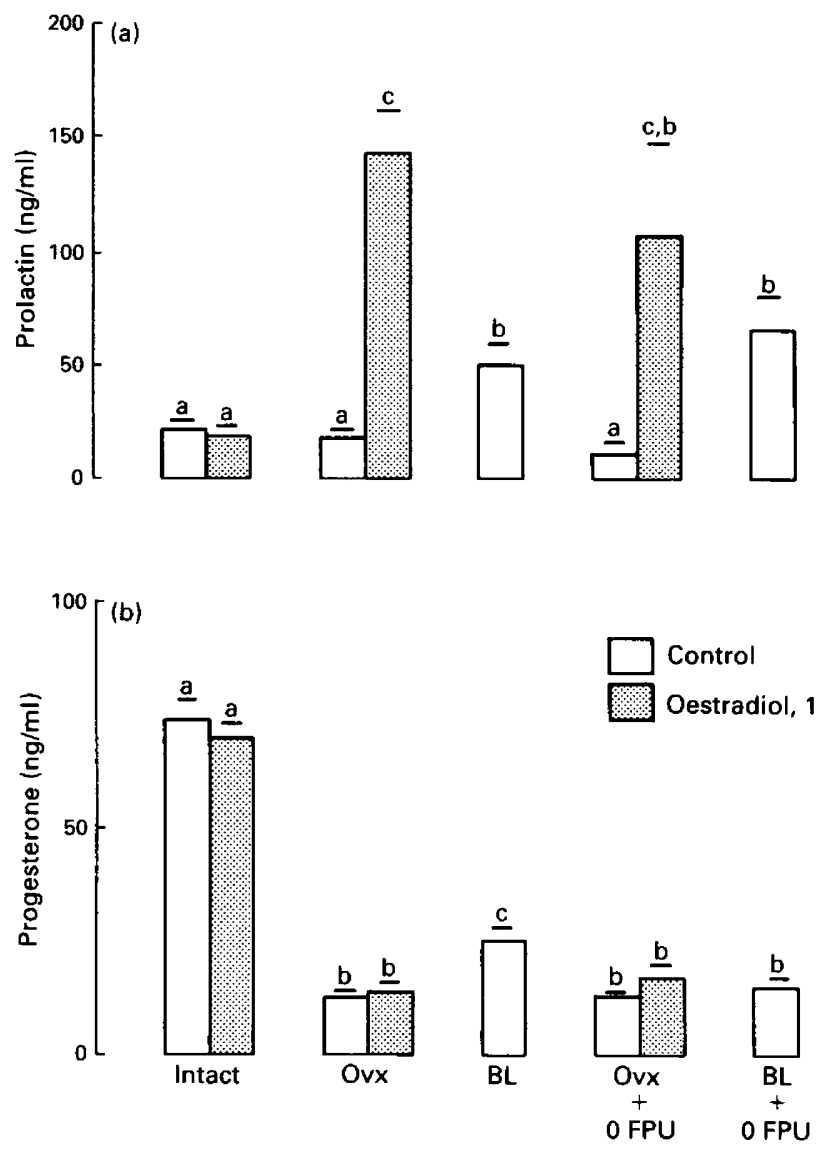

Fig. 4. Effect of ovariectomy (Ovx), bilateral excision of corpora lutea (BL), uterine evacuation ( 0 FPU) and oestradiol treatment (1 1 g, s.c. at 21:00 h on Day 16) on serum prolactin (a) and progesterone (b) concentrations at $09: 00 \mathrm{~h}$ on Day 17 of pregnancy. Values are mean \pm s.e.m. for 8-9 animals; values with different letters are significantly different, $P<0.05$. 


\section{Effect of conceptus number on serum progesterone and prolactin concentrations (Fig. 3)}

When the number of fetoplacental units was reduced surgically to 2 or 4 on Day 11 of pregnancy, serum prolactin concentration at 18:00 h on Day 13 was not modified, but serum progesterone values were significantly and proportionally reduced. In these two groups the oestradiol treatment did not increase serum progesterone concentrations.

In the group with 4 conceptuses remaining, only the treatment with oestradiol and progesterone (given at 13:00 h) produced a slight but significant stimulation of serum prolactin concentration. In the group with 2 conceptuses left, treatment with progesterone at 10:00 h (Day 13), after oestradiol priming, increased serum prolactin concentration, but a highly significant effect was obtained when progesterone was administered at 13:00 h. This increase was similar to those obtained with the same treatment given to rats with bilateral removal of the corpora lutea and the ovariectomized rats. This increase in serum prolactin was prevented $(P<0.005)$ by previous treatment with progesterone $(5 \mathrm{mg}$ at 13:00 h) on Days 11 and 12 of pregnancy, which elevated serum progesterone to $299 \pm 63 \mathrm{ng} / \mathrm{ml}$. However, the serum prolactin concentrations in these rats were higher than the values in the oil-treated group $(P<0.05)$.

\section{Effect of treatments on Day 16 on serum prolactin and progesterone concentrations 24 h later (Fig. 4)}

Ovariectomy, performed at 9:00 h on Day 16 had no significant effect upon prolactin secretion, and these rats showed no signs of abortion or fetal resorption at autopsy on Day 17, although serum progesterone concentration was significantly lower than in the sham-operated controls. Oestradiol $(1 \mu \mathrm{g})$ given at 21:00 h on Day 16 had no effect on sham-operated rats but significantly stimulated prolactin secretion in the ovariectomized rats. Bilateral removal of corpora lutea diminished serum progesterone concentration and also stimulated prolactin release, but to values significantly lower than in rats ovariectomized and given oestrogen treatment. Removal of all the fetoplacental units at the same time as ovariectomy or excision of the corpora lutea did not modify the effect of these operations alone on serum prolactin, but serum progesterone was significantly lowered after bilateral excision of corpora lutea.

\section{Discussion}

Progesterone is known to be an important factor in the maintenance and enhancement of the prolactin surges induced by mating in the rat. It has been previously shown that progesterone augments and maintains prolactin release in pseudopregnant rats (de Greef \& Zeilmaker, 1978; Murakami et al., 1979; Gorospe \& Freeman, 1981, 1982; Deis \& Alonso, 1985). In the present study with pregnant rats, progesterone administration also stimulated the afternoon prolactin surges on Days 4-8. On Day 10 the surge was absent and progesterone alone was unable to stimulate prolactin release, but the treatment with oestradiol and progesterone was effective. A low secretion of placental lactogen is found on Day 10 of pregnancy (Tonkowicz \& Voogt, 1983). On Day 13, when placental lactogen concentrations are maximal (Tonkowicz \& Voogt, 1983) and serum progesterone values have also increased, oestradiol + progesterone treatments were unable to stimulate prolactin secretion.

Our results, and those of others (Yogev \& Terkel, 1980; Tonkowicz et al., 1983), indicate that, at least during Day 13, feto-placental secretions are important factors in the suppression of the afternoon surge of prolactin and in the lack of response of the hypothalamo-hypophysial axis to ovarian steroid action. Nevertheless, the high progesterone levels at mid-pregnancy seem to play a role on the regulation of prolactin secretion, since their partial suppression by unilateral excision of corpora lutea enabled the acute oestradiol and progesterone treatment to be effective. The effectiveness of the combined steroid treatment in inducing prolactin release was proportional to the reduction in endogenous progesterone and feto-placental factors, and was maximal only in the groups 
when both these factors had been eliminated by bilateral ovariectomy or excision of corpora lutea, because of the consequent disruption of pregnancy. The induction of high progesterone concentration by daily progesterone administration in the rats with only 2 remaining feto-placental units resulted in low prolactin concentrations in spite of oestradiol treatment. The present results suggest that the inhibitory action of progesterone is a direct central effect most probably on the hypothalamo-pituitary axis. Rats in which all the corpora lutea were removed were the only ones in which spontaneous prolactin secretion was induced; it is possible that the oestrogen secreted by the remaining ovarian tissue was sufficient, in the presence of low progesterone levels, to stimulate prolactin release to maximal values. However, we must consider that the partial resorption of the conceptuses and vaginal bleeding observed in this group may have acted as a stressful stimulus and to some extent influenced prolactin release. On the other hand, in ovariectomized animals, progesterone treatment was also needed to obtain a similar effect.

The present results demonstrate that the dual action of progesterone on prolactin secretion, shown with ovariectomized rats (Caligaris et al., 1974) and pseudopregnant rats (Deis \& Alonso, 1985), also acts during pregnancy. There seems to be also a critical period during which progesterone administration seems to be most effective in stimulating prolactin release (see Fig. 3). Generally, administration of progesterone at 13:00 h was more effective than at 10:00 h. Most probably, when progesterone was injected at 10:00 $\mathrm{h}$ the increase in prolactin secretion might have occurred earlier than 18:00 $\mathrm{h}$ (unpublished). However, in the ovariectomized animals, in which progesterone was diminished to very low values and placental lactogen secretion was eliminated by fetal resorption as a consequence of ovariectomy, both times of administration of progesterone were equally and maximally effective in inducing prolactin release in animals primed with oestradiol.

Our results indicate that, by Day 17 onwards, the inhibitory control on prolactin secretion seems to be shifted completely to the high progesterone levels. Although its removal was not stimulatory per se, on Day 17 of pregnancy, it allowed oestradiol to act. It has been previously shown that ovariectomy by itself stimulates prolactin release $24 \mathrm{~h}$ after surgery, when performed on Days 18-20 of pregnancy, and that oestradiol administration enhances this effect (Vermouth \& Deis, 1974; Bussmann et al., 1983). This effect was prevented by progesterone administration (Deis, 1968; Vermouth \& Deis, 1974). An effect similar to that after oestradiol treatment of ovariectomized rats was obtained at the end of pregnancy by removal of corpora lutea or administration of PGF-2 $\alpha$ (Vermouth \& Deis, 1972; Bussman \& Deis, 1979; Bussmann, Keninck \& Deis, 1983) because of the endogenous oestrogen secreted by the non-luteal ovarian tissue. It has been shown (Taya \& Greenwald, 1981) that on Days 14-18 of pregnancy oestradiol production by the ovary is much lower than during late pregnancy and this may explain the minimal effect of corpora lutea removal on Day 16 when compared with corpora lutea removal on subsequent days. The clear stimulatory effect of ovariectomy plus oestradiol on prolactin secretion on Day 17 of pregnancy supports this hypothesis. The increase in prolactin secretion in all these cases is clearly related to the fall in endogenous progesterone concentrations, and not to placental lactogen or other fetoplacental secretions, because the removal of all the conceptuses did not modify significantly the effect already obtained by oestradiol treatment of ovariectomized rats, or by bilateral excision of corpora lutea.

Conflicting results have been published on the luteotrophic effect of oestrogen in pregnant rats. Alloiteau \& Mayer (1967) postulated that oestrogen had a direct luteotrophic effect in the rat, but only in the presence of prolactin or placental lactogen. However, other authors, using hypophysectomized-hysterectomized pregnant rats showed that oestradiol has a luteotrophic effect that is not dependent on circulating prolactin or placental lactogen (Takayama \& Greenwald, 1973; Gibori, Antczak \& Rothchild, 1977). We found that oestradiol was able to increase serum progesterone concentrations in rats with unilaterally excised corpora lutea to values similar to those of the intact rats, but had no effect on rats with only two remaining conceptuses, which suggests that the luteotrophic action of oestrogen in pregnant rats is dependent on high serum concentration of placental lactogen or other placental factors (Fig. 3). The rats with only 2 or 4 
remaining conceptuses had diminished serum progesterone concentration, perhaps owing to the lower quantity of placental lactogen secreted by the remaining placentae (Voogt et al., 1982; Tonkowicz et al., 1983).

In conclusion, we have shown that progesterone changes from a stimulatory to an inhibitory action on prolactin release during pregnancy in the rat. During midpregnancy feto-placental factors play an important role in the inhibition of prolactin secretion but afterwards progesterone remains as the main inhibitory factor.

This work was supported by grants from the BID-CONICET program, Argentina.

\section{References}

Alloiteau, J.J. \& Mayer, G. (1967) Problemes concernant la formation, le maintien et la regression du corps jaunes chez le rat. Archs Anat. Microsc. 56 (Suppl. 3-4), 189-197.

Alonso, A. (1974) Control hormonal de la secrecion de prolactina en la rata. Doctoral thesis, Universidad Nacional de Cordoba, Argentina.

Bussmann, L.E. \& Deis, R.P. (1979) Studies concerning the hormonal induction of lactogenesis by prostaglandin F2 alpha in pregnant rats. J. Steroid Biochem. 11, 1485-1489.

Bussmann, L.E., Koninckx, A. \& Deis, R.P. (1983) Effect of estrogen and placental lactogen on lactogenesis in pregnant rats. Biol. Reprod. 29, 535-541.

Caligaris, L., Astrada, J.J. \& Taleisnik, S. (1974) Estrogen and progesterone influence on the release of prolactin in ovariectomized rats. $J$. Endocr. $\mathbf{6 0}$, 205-215.

de Greef, W.J. \& Zeilmaker, G.H. (1978) Regulation of prolactin secretion during the luteal phase in the rat. Endocrinology 102, 1190-1198.

Deis, R.P. (1968) Oxytocin test to demonstrate the initiation and end of lactation in rats. $J$. Endocr. $\mathbf{4 0}$, $1-3$.

Deis, R.P. \& Alonso, N. (1985) Role of oestrogen on prolactin release induced by progesterone in pseudopregnant rats. In Prolactin-Basic and Clinical Correlates, pp. 307-314. Eds R. M. MacLeod, M. O. Thorner \& U. Scapagnini. Liviana Press, Padova.

Freeman, M.E. \& Sterman, J.R. (1978) Ovarian steroid modulation of prolactin surges in cervically stimulated ovariectomized rats. Endocrinology 102, 1915-1920.

Gibori, G., Antczak, E. \& Rothchild, I. (1977) The role of estrogen in the regulation of luteal progesterone secretion in the rat during the period after day 12 of pregnancy. Endocrinology 100, 1483-1495.

Gorospe, W.C. \& Freeman, M.E. (1981) An ovarian role in prolonging and terminating the two surges of prolactin in pseudopregnant rats. Endocrinology 108, 1293-1298.

Gorospe, W.C. \& Freeman, M.E. (1982) The imprint provided by cervical stimulation for the initiation and maintenance of daily prolactin surges: modulation by the uterus and ovaries. Endocrinology 110 , 1866-1970.

Kelly, P.A., Shiu, R.P.C., Robertson, M.C. \& Friesen, H.G. (1975) Characterization of rat chorionic mammotropin. Endocrinology 96, 1187-1195.

Murakami, N., Takahashi, M. \& Suzuki, Y. (1979) Indispensable role of peripheral progesterone level for the occurrence of prolactin surges in pseudopregnant rats. Biol. Reprod. 21, 263-268.

Robertson, M.C. \& Friesen, H.G. (1981) Two forms of rat placental lactogen revealed by radioimmunoassay. Endocrinology 108, 2388-2390.

Smith, M.S. Neill, J.D. (1976) Termination at midpregnancy of the two daily surges of plasma prolactin initiated by mating in the rat. Endocrinology 98 , 696-701.

Snedecor, G.W. \& Cochran, W.G. (1967) Statistical Methods, 2nd edn. Iowa State University Press, Ames.

Takayama, M. \& Greenwald, G.S. (1973) Direct luteotropic action of estrogen in the hypophysectomizedhysterectomized rat. Endocrinology 92, 1405-1418.

Taya, K. \& Greenwald, G.S. (1981) In vivo and in vitro ovarian steroidogenesis in the pregnant rat. Biol. Reprod. 25, 683-691.

Tonkowicz, P.A. \& Voogt, J.L. (1983) Termination of prolactin surges with development of placental lactogen secretion in the pregnant rat. Endocrinology 113, 1314-1318.

Tonkowicz, P.A. \& Voogt, J.L. (1984) Ovarian and fetal control of rat placental lactogen and prolactin secretion at midpregnancy. Endocrinology 114, 254-259.

Tonkowicz, P.A., Robertson, M. \& Voogt, J.L. (1983) Secretion of rat placental lactogen by the fetal placenta and its inhibitory effect on prolactin surges. Biol. Reprod. 28, 707-716.

Vermouth, N.T. \& Deis, R.P. (1972) Prolactin release induced by prostaglandin $\mathrm{F} 2$ alpha in pregnant rats. Nature, New Biol. 238, 248-250.

Vermouth, N.T. \& Deis, R.P. (1974) Prolactin release and lactogenesis after ovariectomy in pregnant rats: effect of ovarian hormones. $J$. Endocr. 63, 13-20.

Voogt, J.L. (1980) Regulation of nocturnal prolactin surges during pregnancy in the rat. Endocrinology 106, 1670-1676.

Voogt, J.L., Robertson, M. \& Friesen, H. (1982) Inverse relationship of prolactin and rat placental lactogen during pregnancy. Biol. Reprod. 26, 800-805.

Yogev, L. \& Terkel, J. (1978) The temporal relationship between implantation and termination of nocturnal prolactin surges in pregnant lactating rats. Endocrinology 102, 160-165.

Yogev, L. \& Terkel, J. (1980) Timing of termination of nocturnal surges in pregnant rats as determined by the number of fetuses. J. Endocr. 84, 421-424.

Received 13 August 1985 